\title{
REGIÃO
}

\section{Rogério Haesbaert}

Universidade Federal Fluminense

Região é um dos conceitos mais difundidos e tradicionais da Geografia. Sua concepção remonta às origens do próprio pensamento geográfico, através do contraponto entre leituras do espaço mais gerais, "sistemáticas" e mais específicas, descritivas. Colocamse lado a lado, assim, a Corografia e a Geografia Mundial (Ptolomeu), a Geografia Universal e a Geografia Especial (Bernard Varenius), a Geografia Geral ou Sistemática e a Geografia Particular ou Regional. De modo bastante amplo, pode-se dizer que esse duo reflete o grande debate epistemológico entre correntes mais racionalistas e mais empiristas ou nomotéticas e idiográficas. Momentos de maior valorização da descrição e das diferenças ou particularidades em detrimento das semelhanças e generalizações e, em decorrência disso, da busca de uma cientificidade geográfica, tendem a estabelecer o primado da Geografia Regional sobre a Geografia Geral ou Sistemática.

Esse debate se configura também entre os grandes geógrafos Humboldt e Ritter, no início do século XIX, mas a região (ou seu correlato, a paisagem, vista em sua diferenciação morfológica) foi o conceito geográfico por excelência durante um período importante, especialmente as primeiras décadas do século $X X$, em contextos como o francês e o anglo-saxônico. Isso ocorreu a partir da caracterização da Geografia como disciplina corológica (Alfred Hettner) ou definida como o estudo da diferenciação de áreas (Richard Harshorne, cujo empirismo e/ou racionalismo foi variável ao longo de sua obra).

Embora recorrente, região é um conceito que, em meio a idas e vindas, "mortes e ressurreições" ao longo da história da disciplina, reaparece sempre de forma distinta, o que se manifesta numa grande polissemia. Assim, é preciso reconhecer a importância de seu uso ao mesmo tempo como categoria da prática, amplamente difundida no âmbito do senso comum, cotidiano; como categoria analítica, no circuito acadêmico, e como categoria normativa, na esfera, por exemplo, das políticas estatais de planejamento. Ao mesmo tempo que se distinguem, essas perspectivas se cruzam, sendo indispensável, em diversos momentos, estabelecer o diálogo entre elas. Dependendo da corrente teórica, a região pode estar mais próxima do espaço vivido onde se moldam as identidades regionais, por exemplo. Em outros, quando se enfatiza uma visão mais pragmática, podemos ter forte presença das "regiões-plano" ou "regiões-programa", vinculadas ao planejamento regional.

Como todo conceito funda e/ou responde a uma questão, devemos nos indagar sobre qual seria a principal problemática mobilizada pelo conceito de região e que, justificando a permanência do termo, de alguma forma se mantém ao longo da história do pensamento geográfico. Pode-se afirmar que, como base para a grande distinção - e relação - entre Geografia Geral ou Sistemática e Geografia Regional, o todo e as partes, região diz respeito em primeiro lugar às questões elementares que envolvem a diferenciação do espaço geográfico, permitindo identificar suas partes ou singularidades através de diferenças de natureza ou tipo e diferenças de grau (como as desigualdades).

Mesmo como categoria da prática, difundida pelo senso comum, comumente região é tratada como sinônimo de porção do espaço delimitada por algum critério ou dotada de alguma característica própria, distintiva. Numa leitura bastante genérica, que alguns preferem associar a processos mais amplos de regionalização, mais do que a região propriamente dita, essa concepção é retomada no âmbito acadêmico, ao serem discutidos os critérios e/ou as características 
mais marcantes na diferenciação do espaço geográfico ou, se quisermos, na definição de uma região.

Para muitos, trata-se ainda hoje de uma das questões geográficas fundamentais: ao lado de outras ligadas à extensão/escala e à localização/situação de um fenômeno, em que medida e com base em que critérios o espaço geográfico pode ser diferenciado? Desse modo, a regionalização como método intelectual para analisar o espaço e nele encontrar partes, "recortes" (ou, como preferimos, hoje, "articulações") regionais, pode utilizar distintos caminhos, dependendo dos critérios, do local e da extensão ou escala do espaço geográfico pertinentes ao pesquisador. Quando a grande questão da diferenciação do espaço é tomada da forma mais genérica temos como resultado "regiões simples" ou "elementares" onde qualquer critério de diferenciação pode ser utilizado, definido pelo pesquisador conforme os propósitos de sua investigação. 0 ápice desse ponto de vista foi a regionalização como classificação de áreas da Geografia neopositivista, bastante criticada pelos geógrafos da chamada escola francesa de Geografia.

Em relação aos critérios de diferenciação, alguns poderão responder que o elemento ou, se quisermos, a dimensão do espaço geográfico mais relevante diz respeito aos aspectos naturais. Como ocorria numa das primeiras concepções de região, a região natural, elementos relativos à Geografia Física seriam os mais importantes pela diferenciação do espaço geográfico. Interpretações como aquelas do chamado determinismo ambiental defenderiam essa leitura, na qual a própria ação humana estaria subordinada a ou seria uma decorrência do meio físico-natural.

Outros geógrafos fariam restrições a essa concepção mais generalizante e racionalista em que um elemento, no caso, natural (sobretudo o clima), acabava sempre por vencer. Numa primeira flexibilização dessa ideia alguns propuseram que o elemento físico que melhor definiria a região poderia variar conforme a área e a escala (numa o clima, noutra o relevo, por exemplo). Foi o caso de Paul Vidal de la Blache num de seus primeiros trabalhos. Mas foi ele também, enquanto autor clássico que defendeu distintas concepções de região, um dos proponentes de uma região que obrigatoriamente vinculava o natural (o "meio") e o cultural (o "homem").

Autores ditos de modo muito simplificado lablacheanos condenaram as regiões simples ou elementares, constituídas por um único ou apenas um grupo de propriedades e demandaram efetivamente como região geográfica aquela que reunisse, num mesmo conjunto, todas as propriedades ou dimensões. Surgia assim a região complexa ou síntese. Região só existiria de fato se correspondesse a um amálgama unitário e coeso (não obrigatoriamente uniforme), uma integração de diversos elementos físico-naturais e humanoculturais, a chamada "região geográfica" em sentido estrito. Nascia o período áureo da Geografia Regional - verdadeiro paradigma da Geografia como um todo, com a região transformada quase num personagem, uma "entidade viva", um dado que caberia ao geógrafo reconhecer, principalmente através da morfologia da paisagem identificada em trabalho de campo. Daí a analogia entre região e paisagem (morfológica).

Outra questão nesse debate sobre a integração ou unidade geográfica regional (entre físico e humano e rural e urbano, por exemplo) é a da escala. Ainda que muitos geógrafos tenham reconhecido que o principal elemento integrador (ou estruturador) da diferenciação poderia variar conforme a escala, grande parte optou por considerar como região por excelência apenas aquela correspondente a uma escala intermediária entre os níveis local e nacional. Mesmo assim, é claro, dependendo da extensão do Estado nação, diversas escalas regionais poderiam ser delineadas (como, no caso do Brasil, as micro, meso e macrorregiões oficialmente reconhecidas).

Para outros geógrafos e "cientistas regionais" (em geral economistas) o principal elemento diferenciador/ identificador de regiões refere-se à dinâmica econômica - nascem assim regiões como a região polarizada ou funcional urbana, comandada pelas diferentes funções econômicas de cada centro urbano e a hierarquia estabelecida entre eles, especialmente através do seu papel comercial e de prestação de serviços. Essa abordagem funcionalista da região teve origem na região nodal de geógrafos como Halford Mackinder e o próprio La Blache. Ela foi sofisticada nos anos 1930 por teorias como a do lugar central de Walter Christaller. Em outras bases filosóficas, como a materialista dialética, encontramos a região como produto da divisão espacial capitalista do trabalho ou das relações desiguais e combinadas entre centros e (semi)periferias. A força dessas concepções faz com que a disciplina que até hoje mais dialogou com a Geografia através do conceito de região seja a Economia. Daí o fato de que muitas das abordagens mais difundidas de região estejam focadas sobretudo na reprodução econômica, enfatizando a articulação espacializada das práticas econômicofuncionais.

Entre concepções mais recentes de região, poucas são aquelas que não dão destaque aos processos econômicos. 0 conceito de cidade-região, por exemplo, leva em conta o papel crescente das dinâmicas de urbanização e de metropolização na conformação não apenas hierárquica mas também mais horizontalizada das relações econômicas. 0 aumento da urbanização 
praticamente equivale, em muitos casos, a falar do próprio urbano como região. Outra concepção é a da "região com buracos", de um grupo de geógrafos britânicos, entre os quais Doreen Massey, que considera a dinâmica do capitalismo pós-fordista ou de acumulação flexível e sua articulação espacialmente desigual, criando "buracos", diversas áreas excluídas das redes articuladoras dessa nova dinâmica.

Por mais que as questões da ordem das práticas espaciais vinculadas à produção capitalista do espaço sejam predominantes na definição de região, não podemos, entretanto, ignorar outras abordagens, como aquelas vinculadas a uma matriz cultural fenomenológica, onde aparece a região como espaço vivido, associada às identidades regionais. Além disso, não é raro encontrar uma leitura que, também a partir de processos efetivamente construídos, propõe enfatizar a base política da região, ao relacioná-la com os regionalismos, movimentos políticos de base territorial na busca por autonomia frente ao Estado nação. Por mais que o conceito de regionalismo tenha extrapolado hoje a escala nacional (com economistas utilizando o termo para a formação de blocos econômicos internacionais, por exemplo), processos regionalistas infranacionais continuam firmes.

É importante lembrar também a natureza política da região presente em sua própria origem etimológica, pois o termo provém do latim "regere" - dirigir, comandar, e tem a ver com "regio", relativo ao rei e seus recortes políticos, mas também à raiz "reg", indicativa de um movimento em linha reta. Ao mesmo tempo que designava uma porção de terra sob algum comando ou jurisdição (neste sentido aproximando-se muito da concepção de território), significava também uma linha, um limite, uma direção.

Daí é possível inferir que, desde a origem, regionalizar, recortar o espaço, delimitá-lo, é também uma forma de estabelecer limites e indicar direções. Com isso, uma das grandes questões que até hoje se coloca nos processos de regionalização é o impasse metodológico envolvendo a questão dos limites e da configuração espacial das regiões. Em termos de configuração geográfica há um debate entre os defensores de regiões zonais, espaços relativamente homogêneos dotados de continuidade (interna) e contiguidade (com outras regiões), mais tradicionais, e aqueles que defendem regiões basicamente reticulares, onde mais importante do que estabelecer linhas limítrofes é definir centros e redes articuladoras. Apesar do domínio cada vez mais evidente das articulações e desarticulações em rede, o simples fato de que até hoje o planejamento regional de algum modo continua tomando como referência unidades político-administrativas zonais (fundamento geográfico do Estado), esse debate não está superado.

É assim que a região, longe de desaparecer, tem se tornado cada vez mais complexa: móvel, instável, de limites fluidos, ao mesmo tempo verticalmente hierarquizada (com papel dominante e/ou subordinado) e horizontalmente complementar. Seu desenho varia, portanto, conforme os sujeitos, as escalas de alcance da ação e os interesses em jogo. Sem dúvida, entretanto, antigas questões regionais vêm sendo relidas, como a do caráter integrador dos espaços regionais, incluindo aquele entre natureza e sociedade.

0 fato da sociedade, especialmente sob a economia capitalista globalizada, ter se descolado das bases naturais diferenciadoras do espaço geográfico, não quer dizer, em hipótese alguma, que essa relação possa ser menosprezada. Ao contrário, as reconfigurações regionais terão cada vez mais que responder a uma nova relação sociedade-natureza que minimamente resgate sua indissociabilidade. É o que ocorre, sobretudo, com a noção de biorregião, que não só reconhece os vínculos ainda efetivamente existentes como propõe, na prática, como projeto necessário, um retorno a princípios como o do respeito às condições ambientais e certa autossuficiência regional, evitando o dispêndio de energia com o deslocamento de produtos a longas distâncias. 0 que está em jogo, novamente, é a relevância do caráter integrador na leitura do espaço geográfico que caracterizava os chamados estudos de área, outra vez em pauta. Como essa "integração" é muito variável, desde espaços economicamente mais articulados e intensamente urbanizados até espaços mais fragmentados ou de amplo domínio dos processos naturais, também devem ser flexíveis as concepções de região que utilizamos.

Uma questão que igualmente permanece, neste caso de ordem mais metodológica, é aquela entre a região como um dado ou fato e a região como artifício. Enquanto para alguns os recortes regionais não passam de uma abstração, um artifício ou instrumento analítico do pesquisador, outros encaram a região como um "dado", entidade física configurada claramente no terreno onde nos cabe simplesmente reconhecer sua manifestação. 0 geógrafo Camille Vallaux, no início do século $X X$, já reconhecia que, dada a dificuldade de encontrarmos uma correspondência clara entre os fatos da geografia humana e os da geografia física, a região não passaria de um artifício analítico e um método pedagógico.

O debate, entretanto, continua, e podemos falar de uma região como arte-fato (com hífen), no meio de um continuum que se estende desde o recorte analítico, instrumento metodológico proposto pelo investigador para efeito de sua pesquisa, até o espaço de ações 
concretas de sujeitos sociais que efetivamente constroem articulações regionais, sejam eles hegemônicos (como as empresas e o Estado), sejam subalternos (como os povos tradicionais). Haveria, portanto, pelo menos uma região (e, consequentemente, também, uma regionalização) feita pelos e/ou para "os de cima" e uma região/ regionalização feita pelos e/ou para os "de baixo". Por isso regionalizar, seja como processo concreto de construção de regiões (pela divisão do trabalho, pelo regionalismo e/ou pelas identidades regionais), seja como recorte analítico variável segundo os critérios propostos pelo pesquisador, é sempre uma forma, mais explícita ou mais sutil, de exercício do poder. Nesse exercício político é fundamental que se reconheçam as partes, divisões, sem, contudo, menosprezar os processos conjuntos de des-articulação.

\section{Referências bibliográficas}

ALLEN, J.; MASSEY, D. e COCHRANE, A. 1998. Rethinking the Region. Londres : Routledge.

ENTRIKIN, J. (org.) 2008. Regions : critical essays in Human Geography. Ardershot e Burlington : Ashgate.

FRÉMONT, A. 1980. Região : espaço vivido. Coimbra; Almedina.

HAESBAERT, R. 2010. Regional-Global: dilemas da região e da regionalização na Geografia contemporânea. Rio de Janeiro: Bertrand Brasil.

HAESBAERT, R.; NUNES, S. e RIBEIRO, G. 2012. Vidal, Vidais: Rio de Janeiro: Bertrand Brasil.

HARTSHORNE, R. 1939. The Nature of Geography. Annals of the Association of American Geographers, XXIX.

JOHNSTON, R. ; HAUER, J. e HOEKVELD, A. (orgs.) 1990. Regional Geography: current developments and future prospects. Londres e Nova York : Routledge.

LENCIONI, S. 1999. Região e Geografia. São Paulo: Edusp. 